\title{
Percepções
}

Júlio Mendonça *

\section{A poesia, o cinema e a holossignia}

Júlio Mendonça é poeta, doutor em Comunicação e Semiótica pela Pontifícia Universidade Católica (PUC) - São Paulo e coordena o Centro de Referência Haroldo de Campos, na Casa das Rosas. Foi o curador da exposição “Esdrúxulo! 100 anos da morte de Augusto dos Anjos" e organizou o livro "Poesia (Im)Popular Brasileira". Publicou o livro "Democratizar a participação cultural". <juliomendoncaz58@gmail.com> ORCID: 0000-0003-0842-4011
Resumo Este artigo tem por objetivo discutir questões comuns ao cinema e à poesia experimentais: a autoconsciência da linguagem, a atenção à materialidade dos signos e dos meios e o interesse pela hibridização de linguagens são os principais pontos em comum destes dois campos de criação experimental. Mas, sobretudo, poesia e cinema experimentais atuam balizados pela tensão entre os limites físico-corporais da percepção humana e o desejo de uma arte que presentifique o virtual. 0 artigo se propõe a pensar a questão com base nos conceitos de intersemiose e holossignia.

Palavras chave Poesia, Cinema, Percepção, Holossignia.

\section{Poetry, cinema and holosignia}

Abstract This article aims to discuss issues common to experimental cinema and poetry: self-awareness of language, attention to the materiality of signs and means and interest in the hybridization of languages are the main points in common of these two fields of experimental creation. But above all experimental poetry and cinema are marked by the tension between the physical-corporeal limits of human perception and the desire for an art that presentify the virtual. This article proposes to think the question based on the concepts of intersemiosis and holosignia.

Keywords Poetry, Cinema, Perception, Holosignia. 
Introdução

O presente texto nasceu do desejo de pensar possíveis respostas para duas perguntas: o que têm em comum as buscas da poesia e do cinema experimentais?; de que modo influirá na poesia e no cinema o desenvolvimento de formas multissensoriais de virtualização? São perguntas, provavelmente, ambiciosas demais para um texto de proporções reduzidas, mas tentarei refletir um pouco sobre elas com o auxílio dos estudos semióticos, da teoria do cinema e dos estudos da narrativa no meio digital.

Roman Jackobson 1969 caracterizou a poesia como um "estado de autoconsciência da linguagem"; essa autoconsciência da linguagem é particularmente decisiva na poesia de caráter experimental, uma vez que ela explora as relações entre sentido e materialidade dos signos e dos meios. O cinema, em suas manifestações de maior autoconsciência, também tem se voltado para a reflexão sobre os meios técnicos que condicionam sua expressão. Ao mesmo tempo, poesia e cinema têm ambicionado, ao longo da história e de diferentes maneiras, alcançar a "imitação integral da natureza" (expressão de André Bazin), o que representa um paradoxo pois significaria presentificar o que é virtual, dar corpo ao que é signo.

Conforme procuro demonstrar ao longo do ensaio, poesia e audiovisual experimentais têm se caracterizado cada vez mais pelo diálogo entre diferentes códigos - pela multi e intermidialidade. Retomando e reformulando um pouco a segunda das duas perguntas iniciais, de que modos a hibridização de linguagens proporcionada pelos meios digitais influirá nos rumos dessas duas artes e em sua relação com o que os poetas concretos chamaram de "realismo total"? O texto se propõe, ao final, a pensar a questão com base nos conceitos de intersemiose e holossignia.

\section{0 cinema ainda não foi inventado}

Para André Bazin (1991, p. 27), o cinema é um fenômeno idealista, como se a ideia que os homens têm feito dele já estivesse projetada em suas mentes. Bem, sem pretender julgar anacronicamente o grande crítico e pensador do cinema, os estudos realizados nos últimos anos sobre as origens do cinema mostram uma relação mais complexa entre o que os homens projetaram e o que o cinema tem sido. Mas o próprio Bazin diz, no mesmo texto: 
A primazia da imagem é histórica e tecnicamente acidental, o saudosismo de alguns pelo mutismo da tela não remonta o bastante na infância da sétima arte; os verdadeiros primitivos do cinema, aqueles que só existiram na imaginação de uns dez homens do século XIX, pensam na imitação integral da natureza. Logo, todos os aperfeiçoamentos acrescentados pelo cinema só podem, paradoxalmente, aproximá-los de suas origens. $\mathrm{O}$ cinema ainda não foi inventado! (BAZIN, 1991, p.30)

A linha teleológica se quebra e nossa atenção deve se voltar para a origem e, assim, repensarmos o percurso considerando ideias e acidentes. Os aspectos físicos e as técnicas desenvolvidas pelos homens são decisivos no desenvolvimento de uma arte, ainda que isto pareça, para um pensamento logocêntrico (e, neste sentido mais que idealista, ideo-lógico), uma concepção anti-humanista. 0 desenvolvimento das técnicas depende de ideias e acidentes, necessidade e acaso.

Assim, com os estudos recentes do chamado primeiro cinema, sabemos, por exemplo, que, não só os filmes dos primeiros anos do cinema praticamente não tinham narrativa, como o espectador freqüentemente não estava numa posição passiva e estática diante dele, completamente envolvido pela catarse ilusionista que marcará sua relação com o cinema clássico. Os filmes eram exibidos em meio a outras atrações presenciais e curiosidades no ambiente popular dos teatros de variedades. Era uma época de freqüentes transformações nas técnicas, nos modos de produção e nas formas de exibição, e os filmes buscavam chamar a atenção, tanto para a sua relação referencial para com a realidade, quanto para o caráter ilusionista inerente ao dispositivo técnico. É o que um dos mais importantes estudiosos desses primeiros anos do cinema, Tom Gunning chamou de cinema de atrações:

Em primeiro lugar, é um cinema que se baseia na (...) sua habilidade de mostrar alguma coisa. (...) Há um aspecto do primeiro cinema (...) que representa esta relação diferente que o cinema de atrações constrói com seu espectador: as freqüentes olhadas que os atores dão na direção da câmera. Esta ação, que mais tarde é considerada um entrave à ilusão realista do cinema, aqui é executada enfaticamente, estabelecendo contato com a audiência. (...) este é um cinema que mostra sua própria visibilidade, disposto a romper o mundo ficcional auto-suficiente e tentar chamar a atenção do espectador. (GUNNING, 1990, p.60).

Mas, para que possamos prosseguir nossa reflexão com algum método, voltemo-nos um pouco para os instrumentos que a semiótica pode oferecer. A classificação dos signos em ícone, índice e símbolo é a base fundamental da teoria dos signos de Charles Sanders Peirce. Um signo é um ícone se ele apresenta alguma similaridade com o seu objeto, "expressando uma qualidade de sentimento, na identidade formal e material entre signo e objeto" (SANTAELLA, 1995, p.145). Uma imagem e um diagrama são exem- 
plos de signos icônicos. Por estar calcado numa similaridade qualitativa, o ícone é marcado pela ambiguidade, pela abertura e imprevisibilidade. Um índice é um signo que mantém uma conexão física com seu objeto, uma relação efetiva e presencial, que guarda vestígios do objeto. Uma batida na porta e um olhar são signos indiciais. O símbolo, por sua vez, é apenas uma mediação, um signo "cuja virtude está na generalidade da lei, regra, hábito ou convenção de que ele é portador" (SANTAELLA, 1995, p.172). Uma palavra ou um sinal de trânsito são símbolos. Trata-se da instância sígnica mais permeável à previsibilidade e à redundância. Mas o signo no nível simbólico é, ao mesmo tempo, o signo responsável pelo desenvolvimento da capacidade conceitual da linguagem. Sem o símbolo não há metalinguagem.

O primeiro cinema revela um predomínio de relações icônicas e indiciais, tanto no que diz respeito às relações entre as imagens em movimento e à realidade às quais elas se referem, quanto no que concerne às relações entre as imagens e o espectador. 0 regozijo com a recém-conquistada capacidade de mostrar se evidencia na exposição predominante das virtudes de similaridade e indicialidade dessas imagens. Esta é uma outra maneira de entender o que Tom Gunning, no trecho acima citado, observa quando fala de um cinema que mostra sua própria visibilidade e chama a atenção para a freqüência com que os atores olham na direção da câmera.

André Gaudreault propôs a seguinte periodização na formação do "modo de representação fílmica":

- período do filme em plano único: apenas rodagem;

- período do filme em vários planos não-contínuos: rodagem e montagem, mas sem que a primeira seja realizada de maneira verdadeiramente orgânica em função da segunda;

- período do filme em vários planos contínuos: rodagem em função da montagem. (1989, p.20)

É neste terceiro período que a narrativa irá começar a estabilizar o formato-filme. Num primeiro momento, o desenvolvimento da narrativa fílmica será baseado na decupagem sintagmática (montagem) e, logo, na paradigmática (montagem paralela). Mas será a influência da narrativa de origem verbal, do romance ou do teatro, que, a partir de um segundo momento (principalmente com o desenvolvimento do cinema sonoro), será decisiva para a conformação da narrativa fílmica, estabilizará padrões narrativos em "gêneros" cinematográficos (quase todos eles com origem nas artes verbais), e com esses padrões estáveis gerará produtos que, até hoje, mantêm a indústria do cinema. 0 predomínio da palavra como instância estruturadora da narrativa faz, a partir daí, recuar em grande parte as instâncias icônicas e indiciais. É claro que elas ainda comparecem em momentos privilegiados nos filmes, aqui e ali, em maior ou menor grau. Mas é a instância simbólico-conceitual, 
respaldada no hábito ou convenção e na maior previsibilidade, que predomina por meio da quase onipresença da narrativa de origem verbal.

Luis Buñuel, na sua conferência "Cinema: Instrumento de Poesia" (1958), assim se refere a esse cinema de base narrativa literária: "Desgraçadamente, a grande maioria da produção cinematográfica atual parece não ter outra missão: as telas se comprazem no vazio moral e intelectual onde prospera o cinema, que se limita a imitar o romance ou o teatro com a diferença de que seus meios são menos ricos para expressar psicologias" (XAVIER, 1983, p.334)

Assim, a concepção de cinema ficou, durante bastante tempo e para a maioria das pessoas, estabilizada na fórmula do filme. Assim se referia a ela Christian Metz, nos anos 60:

O interesse do público influiu na consolidação da 'fórmula do espetáculo' fílmico, sem dúvida. O grande filme de uma hora e meia com seus complementos (documentário, etc.) de narratividade inferior é uma fórmula. Talvez não dure sempre, mas por enquanto ela agrada bastante, ela é aceita. (...) A fórmula básica, que nunca foi alterada, é aquela que consiste em chamar de 'filme' uma grande unidade que nos conta uma estória e 'ir ao cinema' é ir assistir a esta estória. (METZ, 1972, p.61)

Quando Billy Wilder realiza "Crepúsculo dos Deuses", todo o contexto diegético da época do cinema mudo e do cinema narrativo clássico desenvolvido após o domínio do som está ali subentendido e a narrativa do filme pode se referir a ele de maneira muito sintética, porque sabe-se que o espectador médio já está em pleno domínio daquele contexto (isto é, já incorporou o hábito/convenção). Ironicamente, o personagem que narra a história é roteirista e ao final iremos descobrir que ele a está narrando depois de morto (o que nos faz lembrar Pasolini: "a morte realiza uma montagem fulminante de nossa vida"; a morte, o interpretante [Peirce] conceitual final) (SANTAELLA, 1995).

Entretanto, a latência de outros cinemas possíveis não deixou de despertar o interesse de muitos realizadores. Desde 1916, pelo menos, quando se publicou o manifesto "La Cinematografia Futurista" que propunha "simultaneidades e compenetrações cinematografadas de tempo e espaço (...) para se liberar da lógica" (PERLOFF, 1993) e anunciava a decomposição e a recomposição do universo a partir de nossas fantasias. As ideias desse manifesto encontram eco até hoje, como veremos.

As experiências dos primeiros anos de Abel Gance (suas telas múltiplas), o cinema revolucionário de Vertov, o chamado "cinema puro" de Hans Richter, o inconformismo lúdico e perscrutador de "Entr'Acte", de René Clair, de "Emak Bakia", de Man Ray, "Um Cão Andaluz", de Buñuel e Dali, as animações abstratas de Norman McLaren, são apenas alguns poucos 
exemplos dentre outros tantos, retirados da produção das décadas de 20 a 50, de um cinema inquieto que se pergunta sobre seu modo de expressão e recusa do modo narrativo de raiz literária. Prioriza o movimento centrípeto - "o ícone, onde está o âmago da criação" (Julio Plaza, in PARENTE, 1993, p. 86) em detrimento do movimento centrífugo da comunicação. Embora o cinema brasileiro anterior aos anos 60 não tenha tido uma tradição experimental, podemos lembrar as experiências marcantes, mas isoladas, de Alberto Cavalcanti ("Rien que les Heures", 1926) e Mário Peixoto ("Limite", 1930).

É claro que mesmo o filme mais experimental e refratário à narrativa e à influência da palavra pode ser interpretado em palavras, num enunciado ou numa sequência de enunciados. E é. Evocando Deleuze, André Parente escreve:

\footnotetext{
Deleuze observa, com razão, que o cinema não é uma linguagem, e sim uma massa ou matéria plástica, a-significante e a-sintática, não lingüisticamente formada, embora não seja amorfa e seja formada semioticamente. 'É uma condição, anterior, em direito, ao que condiciona. Não é uma enunciação, não são enunciados, é um enunciável. Queremos dizer que, quando a linguagem se apodera dessa matéria (e ela o faz, necessariamente), dá então lugar a enunciados que vêm dominar ou mesmo substituir as imagens e os signos (...)' (PARENTE,2000, p.25)
}

Parente entende que o "verdadeiro" cinema, narrativo ou não, privilegia o imagético. Ele prefere distinguir a narrativa imagética cinematográfica da narrativa conforme a abordagem semio-lingüística. Do mesmo modo, ele distingue um cinema poético do cinema experimental não-narrativo e extrai, daí, outras consequências (com base em Blanchot, ele não reduz o narrativo ao enunciado de uma história). Mas, aqui, vamos nos ater ao entendimento do narrativo como o enunciado de uma intriga, de um enredo, e vai nos interessar o fato de que o cinema experimental, não-narrativo, disnarrativo ou não-diegético, tem buscado um menor grau de submissão ao discurso verbal, ao enunciado interpretativo, que seus realizadores ainda viam e vêem no cinema narrativo de base diegética literária e mesmo no cinema poético.

\section{Cinema e poesia: caminhos que se cruzam}

Para os formalistas russos, grandes teóricos do primeiro cinema de poesia, tratava-se de, através do emprego de procedimentos como o enquadramento, a decupagem e a montagem, transformar o pensamento do espectador em movimento do pensamento - uma "linguagem interior que reúne as imagens separadas" (PARENTE, 2000, p. 58) Para Roman Jakobson, que propôs a bastante conhecida classificação das funções da linguagem, 
a função poética é aquela que faz a mensagem voltar-se para ela mesma, projetando "o princípio de equivalência do eixo de seleção sobre o eixo de combinação" (JAKOBSON, 1969, p.130). No cinema, os realizadores da vanguarda russa aplicarão esse princípio privilegiando a montagem - a seleção e a combinação das imagens. É nos momentos do filme em que a montagem privilegia a combinação de imagens, que reunidas no pensamento do espectador, alcançam grande condensação de significação, que atingimos um cinema poético. $O$ signo volta-se sobre si mesmo e cria uma relação de similaridade entre ele e o que ele representa. Por isso, a função poética de Jakobson se aproxima do conceito de signo icônico de Peirce. (PLAZA, 2003)

$\mathrm{O}$ conceito de signo icônico, que tende para o vago e o imprevisível, vai influir na concepção de cinema de Pasolini, mas com outras consequências. Para ele, enquanto o cinema de prosa da tradição narrativa "tendencialmente naturalista e objetiva" buscava a comunicação unívoca, o cinema de poesia procurava a criação da ambiguidade e da subjetividade. Tomando como referência as técnicas literárias do "discurso indireto livre" e do "monólogo interior", propõe:

\footnotetext{
A formação de uma 'língua de poesia cinematográfica' implica, por conseguinte, a possibilidade de criar, pelo contrário, pseudo-narrativas escritas na língua da poesia: a possibilidade, em suma, de uma prosa de arte, de uma série de páginas líricas, cuja subjetividade será garantida pelo uso do pretexto da "Subjetiva Indireta Livre": onde o verdadeiro protagonista é o estilo" (apud SAVERINI, 2004, p.45)
}

O cinema de poesia de Pasolini, entretanto, é um cinema fundamentalmente narrativo ("Ao falar, no entanto, de cinema de poesia, entendi sempre falar de poesia narrativa" (SAVERINI, 2004, p.48) Para ele, trata-se de construir narrativas metafóricas. Como veremos mais adiante, outros cinemas não-conformistas recusaram também este caminho e serão influenciados pela música ou pelas artes plásticas ou pelo vídeo.

Quando falamos de cinema, estamos falando de relações e de fronteiras com outras artes: com a literatura e o teatro, no que diz respeito à narrativa ( $a$ abordagem da semiologia em relação à narrativa do cinema parte de um reconhecimento reducionista disto: Gaudreault $(1989$, p.12) descreve o fílmico como um objeto narratológico "complexo", no qual a "narração" envolve o escritural e o cênico); com a fotografia, as artes plásticas, a cenografia, as artes gráficas e os quadrinhos, no que se relaciona ao tratamento visual; com a música e a sonoplastia, no que diz respeito ao som. Os futuristas, que estiveram na ponta de lança da ideia de rompimento da palavra com a ordem sintática com o slogam "palavras em liberdade", viram o cinema como uma arte que poderia sintetizar todas as artes tradicionais.

A poesia experimental surge, justamente, da constatação que Mallarmé resumiu na frase: "nomear um objeto é suprimir três quartas par- 
tes do gozo de um poema" (WILLEMART, 1999, p. 110). Este sentimento de que a palavra não dá conta do mundo foi experimentado, também pelos artistas e pelos teóricos do cinema em relação à imagem.

Durante o século XX, essa poesia que busca questionar seus limites rompeu com a sintaxe (futuristas, cubofuturistas e concretistas), fragmentou o texto e a palavra (e.e.cummings, concretistas), explorou o espaço branco da página como meio expressivo (cubofuturistas, cummings, Pound, concretistas), assumiu uma configuração estruturalmente visual do texto e se propôs "verbivocovisual" (concretistas), incorporou a imagem (poesia concreta, poesia visual), fêz-se objeto (poema-objeto), explorou a gravação e manipulação da voz e dos ruídos (poesia sonora), e, com a tecnologia digital, vem experimentando configurações híbridas de texto, imagem e som, em movimento e transformação, em modo interativo ou não.

Uma poesia que almejou presentificar a síntese estruturada das percepções dos sentidos, organizando as "palavras-coisas" tensionadas no espaço-tempo (plano piloto para poesia concreta, 1958), a poesia concreta e seus posteriores desenvolvimentos experimentais - deu prosseguimento, por outros meios, ao sentimento que um poeta romântico como Wordsworth já expressava no início do século XIX, qual seja, o de que o mundo é um organismo e de que, nas palavras de Edmund Wilson, "o que somos e o que vemos, o que ouvimos, o que sentimos e o que olfateamos estão inextricavelmente relacionados" (1987, p.12) Baudelaire respondeu à impressão de fragmentação diante da cidade moderna, meados do século XIX, com a impressão das correspondências entre os sentidos ("Os perfumes, as cores e os sons se correspondem") e Rimbaud falou em "alquimia dos sentidos".

Durante o século XX, a crescente multiplicação de códigos e linguagens e sua convivência cada vez mais íntima no ambiente urbano, nas artes eruditas, nas industriais e nos meios de comunicação, conduziram aos estudos dos fenômenos da sinestesia e da intersemiose, bem como aos estudos da neuropsicologia sobre as relações entre o verbal e o não-verbal.

A poesia experimental também se valeu dos instrumentos conceituais da semiótica para refletir sobre seus caminhos. Se seus praticantes logo se interessaram pelo conceito peirceano de ícone, vendo na noção que Peirce associa de "qualidade de uma sensação" e na ideia de indeterminação uma forte identificação com o que estavam fazendo, também é verdade que algumas características dessa poesia como a de trazer traços do referente estruturalmente sugeridos e, às vezes, como que vincados, mesmo, nos signos, assim como a de propor a manipulação direta do leitor no poema, são características de viés indicial, na medida em que o índice é um signo de reação que aponta para seu objeto. E, se para Peirce "o significado de um signo é um outro signo", (SANTAELLA,1995) no cenário contemporâneo da proliferação de códigos e linguagens a noção de tradução inter e intracódigos - o processo de intersemiose - aponta para a mutação de linguagem que contamina, cotidianamente, a produção de sentido na vida comum.

De qualquer modo, observando de forma mais abrangente as relações entre cinema e poesia, acreditamos que aquilo que os aproxima 
- e faz com que algumas das questões para as quais seus praticantes voltam sua atenção se tangenciem - é, justamente, o fato de que, para eles, a relação entre espaço e tempo, forma e matéria e a veloz e voraz transformação da experiência do mundo na linguagem é tão intrincada, hoje, que seus instrumentos se mostram insuficientes. Como não podemos mais dizer ou mostrar as coisas como dizíamos/mostrávamos antes e como não se trata de fazer a mimese dessa relação intrincada, mas de construir correlativos objetivos dela, o cinema e a poesia de que precisamos hoje são os que buscam intersecção com outros campos porque seus instrumentos tradicionais já não bastam.

A busca permanente das artes é intersemiótica e sinestésica porque, como dizia Fernando Pessoa, a literatura, como toda arte, é uma confissão de que a vida não basta, e porque o desejo humano de forma é inesgotável e ultrapassa o antropomórfico.

\title{
0 cinemático, o poético e a presentificação do virtual
}

\begin{abstract}
Devemos, portanto, considerar o cinema não como um modo de expressão fossilizado, paralisado na configuração que lhe deram Lumière, Griffith e seus contemporâneos, mas como um sistema dinâmico, que reage às contingências de sua história e se transforma com os novos desafios que lhe lança a sociedade. Como tal, ele vive hoje um dos momentos de maior vitalidade de sua história, momento esse que podemos caracterizar como o de sua radical reinvenção. A transformação por que passa hoje o cinema afeta todos os aspectos de sua manifestação, da elaboração da imagem aos modos de produção e distribuição, da semiose à economia. (MACHADO, 1997, p. 213)
\end{abstract}

Para Bazin, "se o cinema nasceu, isso se deve à convergência da obsessão deles [os técnicos-industriais e os eruditos-imaginativos]; isto é, a obsessão em torno de um mito: o do cinema total". E o mito do cinema total, segundo ele, não tem a ver com a "obra de arte total", mas com o mito guia do "realismo integral, de uma recriação do mundo à sua imagem" (1991, p.31). Bazin identificou no neo-realismo italiano um grande passo nessa direção por "fazer entrar na tela a verdadeira continuidade da realidade" (1991, p.79).

Se esse realismo teve em Vertov um dos seus grandes iniciadores, Peter Kubelka, propugnador de um cinema essencial (e, aliás, devotado a Vertov a ponto de ser responsável pela restauração de seu filme "Entusiasmo"), aponta para os seus limites:

Artistas como Vertov tentaram alcançar uma imagem objetiva apenas colocando a câmera em algum lugar. Mas no momento em que se coloca 
a câmera ali, você escolhe o momento em que começa a imagem; a direção para a qual você aponta a câmera, mesmo se casual, já significa uma decisão. Você faz uma escolha e escolhas já são pessoais, pertencem à realidade pessoal. Nem mesmo a câmera é objetiva. A câmera é uma imagem crua do olho humano, mas está muito longe dele. É uma canhestra imitação técnica do que os olhos fazem (ADRIANO, 2002, p.62).

Também será uma consequência do neo-realismo, que influirá no desenvolvimento da nouvelle vague, a rarefação do enredo, a desconfiança em relação à palavra e, até, a recusa do roteiro (em Godard, por exemplo). Nos anos 60, período marcado pela eclosão do movimento contracultural, vive-se uma desconfiança em relação aos excessos da interpretação, excessos que Susan Sontag chamou de "vingança do intelecto contra arte" no seu famoso livro chamado, justamente, "Contra a Interpretação. Nas artes plásticas, por exemplo, se a arte conceitual adere ao discurso metalingüístico, a pop e a op art investem no icônico e a "minimal art", a "land art" e a "arte povera" voltam-se para os signos indiciais (isto é, aqueles que guardam algum tipo de relação mais direta com a matéria a que se referem).

Philippe Dubois, em seu livro "O Ato Fotográfico", mostrou como a lógica do índice, sua relação de contigüidade existencial com seu meio, sua tendência para o aqui e agora, está vivamente presente na arte contemporânea. $O$ índice é um signo que não está voltado para as abstrações gerais.

Do mesmo modo, há toda uma produção cinematográfica, que tem seus precursores no chamado "cinema puro" dos anos 20 , mas que ganha novo impulso nos anos 50 e 60, que apresenta práticas cinemáticas que, para usar uma expressão de Dubois (1994, p.95), "não representam algo além delas mesmas, elas são por elas mesmas sua própria representação". Os cinemas de Peter Kubelka e Stan Brackage, por exemplo, com as grandes diferenças que apresentam, são marcadamente icônico-indiciais. Os filmes de Andy Warhol recusam o formato-filme (alguns duram várias horas) e desconhecem o roteiro.

A par das experiências do "cinema direto" e do underground americano, multiplicam-se nos anos 60 as instalações, performances, assemblages e vídeo-instalações nas quais o espectador não comparece mais de modo passivo e é chamado a associar as imagens às condições em que ele as consome, transformando sua relação com o meio. Assim é com o trabalho de Nam June Paik, de Valie Export e de Chris Welsky.

Como a mente humana trabalha por associação, é imperativo que, por exemplo, uma imagem associe-se a percepções de outros sentidos. Isto sempre aconteceu no âmbito das artes tradicionais, de modo virtual. Quando Baudelaire explora as "correspondências" (soneto "Correspondances": "Tendo a expansão das coisas infinitas,/(...)/Que cantam os transportes do espírito e dos sentidos"), em meados do século XIX, ele está, no âmbito da poesia exclusivamente verbal, anunciando a busca de conexões sinestésicas que, logo depois, passaria a ser almejada pelas artes, não virtualmente, mas física e materialmente. 
As artes tradicionais superavam virtualmente seus limites físicos para representar a vida ("Meios que não estão dotados de movimento real, como a pintura e a escultura, podem, no entanto, representar a vida, cuja essência é a ação" (ARNHEIM, 1962, p. 8). As artes modernas não se contentam mais com a superação virtual de seus limites, por isto buscam sua superação física. Isto está relacionado ao fato de que os atos de ver, ler ou ouvir não estão mais abstraídos, separados do corpo físico do observador, leitor ou ouvinte. Aliás, eles voltam a ser tudo isto ao mesmo tempo.

A profundidade de campo, cujo desenvolvimento no cinema Bazin considerou um grande avanço para o realismo, começou a ser desenvolvida nos estudos de perspectiva de Leonardo da Vinci e já estava presente no estereoscópio, no início do séc. XIX, que produzia uma imagem tridimensional, conforme salienta Jonathan Crary no livro "Techniques of the Observer", comentado por Arlindo Machado há pouco (Revista Galáxia no.3) : (MACHADO, 2002)

Desde o início, as tecnologias da imagem em movimento estavam voltadas para a superação dos limites físicos das artes da imagem tradicionais.

O manifesto "O Cinema Futurista", de 1916, afirmava a poli-expressividade da nova arte, previa sua capacidade de simultaneidade e interpenetração de tempos e espaços e de dramatizar estados da mente e, inclusive, de mostrar palavras em movimento e letras animadas, o que antecipava a poesia digital de hoje.

Em 1956, o inventor e empresário Morton Heilig lançou o "Simulador Sensorama", engenhoca que pretendia oferecer a sensação de experiência real através do uso multimídia de imagens em três dimensões, sons e aromas. É considerado um precursor das tecnologias da realidade virtual.

Em meados dos anos 60, Ivan Sutherland, com financiamento para pesquisa com finalidade militar, desenvolveu o primeiro processo de simulação virtual.

Em 1970, Gene Youngblood falou em "cinema expandido", prevendo a expansão do cinema para o vídeo e o computador.

Esta é uma enumeração rápida e tosca do processo, na verdade, muito mais rico e complexo, da busca de meios físicos para superar os limites físicos das formas tradicionais de representação. Não é objetivo deste trabalho deter-se na história desse processo.

As novas tecnologias da virtualidade apontam para a possibilidade de ampliação da interatividade e da multisensorialidade, através da confluência de diferentes meios e linguagens. Os computadores são máquinas de simulação e já incorporaram o vídeo e o cinema. Permitem, por exemplo, sincronismo preciso entre eventos virtuais e ações reais. 0 tipo de "comunicação todos-todos" (LEVY, 1997, p.113), hoje comum na Internet, nos chats, começa a se desenhar para a produção e troca de imagens, e já é comum a edição on-line de fragmentos de áudio e vídeo.

Com os meios digitais, as formas narrativas devem se renovar e as experiências multinarrativas de Resnais ("Smoking, No Smoking") encontram neles condições mais promissoras, como, aliás, outros já observaram. Por não serem lineares, as formas narrativas no espaço digi- 
tal lidam com hipóteses e admitem significados plurais (MURRAY, 2003, p.132). Esses meios são basicamente indiciais nas interfaces, fundamentalmente icônicos nas simulações e reconfiguram as instâncias simbólicas das linguagens, que, como é próprio delas, continuarão a tender para a generalidade e o convencional.

Leonardo desenvolveu a "perspectiva complexa" - uma mistura de perspectiva natural com a artificial - pois, como observou, "nenhuma superfície pode ser vista como realmente é porque o olho que a vê não está equidistante de todas as suas bordas" (RICHTER,1983, p.109); Gombrich nos chamou a atenção para o fato de que entre a representação e a chamada realidade o que existe é a ilusão referencial e Barthes escreveu, no livro "Aula", que a "linguagem humana é sem exterior: é um lugar fechado" (BARTHES, 1997, p.16). Portanto, o virtual não é, de forma nenhuma, algo novo na cultura humana e, particularmente, nas artes. O virtual é o que a cultura procura atualizar (em linguística, "atual" está relacionado com o ato de fala "[ou parole, na oposição saussuriana langue/parole]" [Dicionário Houaiss], isto é, o ato sígnico que se realiza, que se pratica). As tecnologias estão criando próteses para nos fazer imergir fisicamente no virtual. As transformações que elas estão trazendo para nossa percepção e nossa atuação nos encantam continuamente pelo seu poder multifacetado, não-linear e não-mimético de representação, talvez como os contemporâneos do surgimento do cinema se encantaram. É possível que logo as consideremos, também, "canhestras imitações técnicas". Se a experiência proporcionada por essas próteses é uma atualização provisória e aberta de interações de linguagens produzidas por números, é bom lembrar a observação de Peirce de que "o mundo real não pode ser distinguido de um mundo fictício por nenhuma descrição. Nada, a não ser um signo dinâmico ou indicial pode realizar tal propósito" (PEIRCE apud SANTAELLA, 1995, p.159)

Esse desejo de representação integral ("imitação integral da natureza" [Bazin]; "realismo total” [poesia concreta]) foi descrito assim por Roland Barthes:

\footnotetext{
Não se pode fazer coincidir uma ordem pluridimensional (o real) e uma ordem unidimensional (a linguagem). Ora, é precisamente a essa impossibilidade topológica que a literatura não quer render-se. Que não haja paralelismo entre o real e a linguagem, com isso os homens não se conformam, e é essa recusa, talvez tão velha quanto a própria linguagem, que produz, numa faina incessante, a literatura. (BARTHES, 1978, p.22).
}

O grifo na palavra topológica é meu porque acredito que, de fato, o ponto crucial diz respeito ao tópos, o lugar, isto é: a presença. Se linguagem e mundo não podem coincidir fisicamente no mesmo lugar, diferentes formas de linguagem podem entremear-se e interpenetrar-se.

Há poucos anos um dos poetas concretos, Décio Pignatari, voltou a se manifestar sobre este tema tão caro aos criadores daquele movimento: 
"Virá o movimento, cores não irisadas virão. Haverá um novo espectador. E um som que corresponda: uma holofonia para uma holografia. Uma holossignia ${ }^{1}$. Um grande espetáculo hologrâmico, unindo foto, cine, televisão" (1995, p.148). Aqui, também, a confluência física de diversos meios com seus códigos aponta para a possibilidade da linguagem intersemiótica inclusiva. A antevisão do designer de linguagem Pignatari (era assim que ele caracterizava a função do poeta) não é muito diferente do que o designer e diretor de cinema Keiichi Matsuda pensa que será o que ele chama de hiper-realidade:

Nossas realidades físicas e virtuais estão cada vez mais interligadas. Tecnologias como Realidade Virtual, realidade aumentada, vestíveis e internet das coisas estão apontando para um mundo onde a tecnologia envolverá todos os aspectos de nossas vidas. Será a cola entre cada interação e experiência, oferecendo possibilidades surpreendentes, e ao mesmo tempo controlando a forma como entendemos o mundo ${ }^{2}$.

Esperemos que o novo espectador não assista, apenas, e possa participar ativamente com acaso e necessidade, sofrimento e liberdade.

1 Décio Pignatari forjou o termo holossignia a partir da palavra grega "holo" - que significa totalidade, unidade, o todo - e "signia" - isto é, a condição sígnica, tão humana.

2 http://hyper-reality.co/, página acessada em 18 de janeiro de 2018

\section{Bibliografia}

ADRIANO, Carlos e VOROBOW, Bernardo. Peter Kubelka: A Essência do Cinema. São Paulo: Babushka, 2002.

ARNHEIM, Rudolf. Arte y Percepción Visual. Buenos Aires: Eudeba, 1962.

BARTHES, Roland. Aula. São Paulo: Cultrix, 1978.

BAZIN, André. o Cinema - Ensaios. São Paulo: Brasiliense, 1991.

COSTA, Flávia Cesarino. o Primeiro Cinema. São Paulo: Scritta, 1995.

DELEUZE,Gilles. A imagem-tempo. São Paulo: Brasiliense, 1990.

DUBOIS, Philippe. 0 Ato fotográfico. Campinas, Papirus, 1994.

GAUDREAULT, André. Du Litteraire au Filmique - Sisteme du Recit. Paris: Klincksieck, 1989. GUNNING, Tom. The cinema of attraction: early cinema, its spectator, and the avant-garde. London: Britsh Film Institute, 1990.

HILLIS, Ken. Tecnologias da Realidade Virtual: Elementos para uma Geografia da Visão. In: Cibercultura On Line - Contribuições à Crítica da Razão Tecnológica. Publicação eletrônica, UFRGS (http://members.fortunecity.com/cibercultura/vol.1/hillis.html).

JAKOBSON, Roman. Lingüística e Comunicação. São Paulo: Cultrix, 1969.

LANDOW, George P. Hypertext 2.0. Baltimore: The John Hopkins University Press, 1997.

LEVY,Pierre. O que é o Virtual? São Paulo: E; 34, 1997.

MACHADO, Arlindo. Pré-cinemas e pós-cinemas. Campinas, Papirus, 1997.

MACHADO, Arlindo. A Emergência do Observador. In: Revista Galáxia no 3. São Paulo: Educ, 2002. 
METZ, Christian. A Significação do Cinema. São Paulo: Perspectiva, 1972.

MURRAY,Janet H. Hamlet no Holodeck - O Futuro da Narrativa no Ciberespaço. São Paulo: Itaú Cultural: Unesp, 2003.

PARENTE, André. Imagem-máquina: a era das tecnologias do virtual. São Paulo, Editora 34, 1993. Narrativa e Modernidade - Os Cinemas Não-Narrativos do Pós-Guerra. Campinas:Papirus, 2000.

PERLOFF,Marjorie. Poetry On \& Off the Page - Essays for Emergent Occasions. Evanston: Northwerstern University Press, 1998.

PERLOFF, Marjorie. 0 momento futurista: Avant-garde, avant guerre e a linguagem da ruptura. São Paulo, Edusp, 1993.

PIGNATARI,Décio. Letras, Artes, Mídia. São Paulo: Globo, 1995.

PLAZA, Julio. Tradução intersemiótica. São Paulo, Perspectiva, 2003.

RICHTER, Jean Paul. The Notebooks of Leonardo da Vinci. New York: Dover Publications, 1983. RISÉRIO, Antonio. Ensaio Sobre o Texto Poético em Contexto Digital. Salvador: Fundação Casa de Jorge Amado, 1998.

SANTAELLA, Lúcia. A Teoria Geral dos Signos. São Paulo: Ática, 1995.

SAVERNINI,Érika. Índices de um Cinema de Poesia. Belo Horizonte: UFMG, 2004.

WILLEMART, Philippe. Bastidores da criação literária. São Paulo: Iluminuras, 1999.

WILSON, Edmund. 0 Castelo de Axel. São Paulo: Cultrix, 1987.

XAVIER, Ismail (org.). A Experiência do Cinema. Rio de Janeiro: Graal, 1983. 